\title{
Vertical Distribution Characteristics of Outdoor Particles Concentrations in High-Rise Buildings
}

\author{
Xin Zhang*, Yuesheng Fan**, Wanqing Yu, Huan Wang, Bingbing Niu, Mengyue Li \\ School of Building Services Science and Engineering, Xi'an University of Architecture and Technology, \\ No.13 Yanta Road, Xi'an, Shaanxi, China
}

Received: 11 April 2020

Accepted: 11 August 2020

\begin{abstract}
With speeding up urbanization in China, it is important to understand the vertical distribution characteristics of outdoor particulate matter concentrations of high-rise buildings. A high-rise building at different heights $\left(1^{\text {st }}, 7^{\text {th }}, 11^{\text {th }}, 17^{\text {th }}, 23^{\text {th }}\right.$, and $27^{\text {th }}$ floors $)$ in a university in Xi'an was tested and analyzed in this paper. Test time was 8:00, 12:00, 15:00, 15:00 and 22:00, respectively. The results showed that the concentration of each particulate matter changed the same trend roughly with the increase of vertical height at 8:00 and 22:00, as well as at 15:00 and 18:00. While the mass concentration of each particle showed a trend of first increased, then decreased and next then increased with the height increased when the time was 12:00. It caused by the inverse temperature. The particles between 0 and $1.0 \mu \mathrm{m}$ accounted for more than $99.4 \%$ during the testing. There were mainly small particles in the atmosphere. $\mathrm{PM}_{1.0} / \mathrm{PM}_{10}$ and $\mathrm{PM}_{2.5} / \mathrm{PM}_{10}$ all showed a trend of first decreased and then increased at different vertical height. The highest points of $\mathrm{PM}_{2.5} / \mathrm{PM}_{10}$ and $\mathrm{PM}_{1.0} / \mathrm{PM}_{10}$ increased by $9.63 \%$ and $8.2 \%$ respectively from the lowest points, and the ratio was the highest at 15:00. At the same time, outdoor meteorological conditions would also affect the concentration distribution of particulate matters. This paper provides a reference for the development of high-rise buildings and the effective control of particulate matter concentration in high-rise buildings.
\end{abstract}

Keywords: high-rise building, particulate matters, vertical distribution, Xi'an

\section{Introduction}

With the vigorous development of the world's economy in recent years, development of urbanization has also achieved unprecedented development [1, 2]. Large-scale popularity of high-rise buildings and extra high-rise buildings caused people's space not only limited to the ground, but also increased from the

*e-mail: 2601084634@qq.com

**e-mail: fanyuesheng@xauat.edu.cn ground to a height of $100 \mathrm{~m}$ from the ground, even taller $[3,4]$. However, pollution of atmospheric particulate matters was more seriously now [5]. It would cause the visibility of the atmosphere of decline, and seriously affects people's normal travel and transport, but also it also caused different degrees of harm to the human body [6], even death [7-9]. However, people spend as much as $80-90 \%$ of their time indoors [10]. The dirty outdoor air would enter the room through the doors and windows of the building and the fresh air system, and it would cause different degrees of indoor pollution. Therefore, good indoor environmental hygiene is particularly important. 


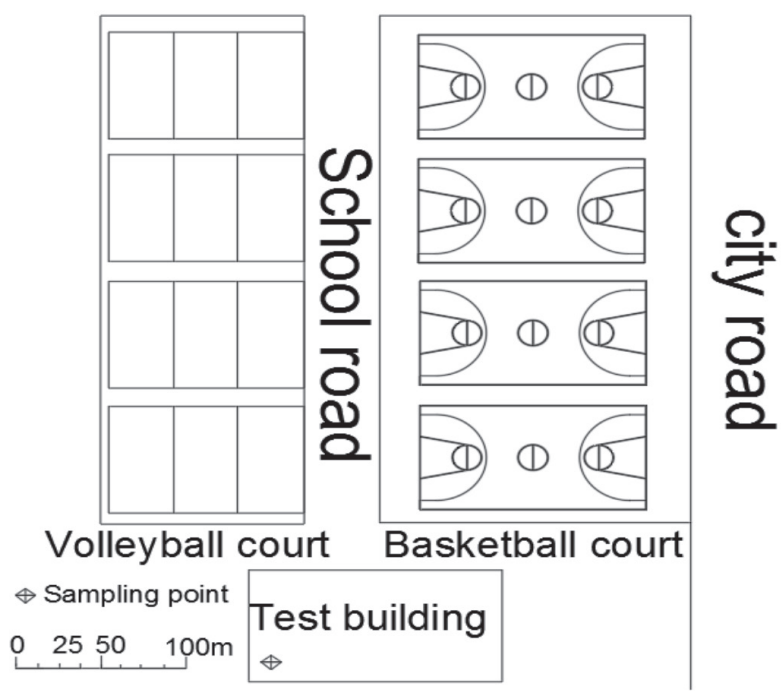

Fig. 1. The plane location map of test construction.

The vertical concentration distribution characteristics of high-altitude air pollutants have a more important significance for people living on different height floors $[11,12]$.

Many researchers from different countries had conducted many studies on monitoring atmospheric particulates concentration now [13-17]. Like distribution of particulate matters [13, 14], the correlation with other pollutants $[15,16]$, the comparison of the distribution before and after in heating time in winter [17], and vertical distribution of near-surface particulates [18]. Some of the results had achieved, and it based on monitoring urban ground areas. Changes in the concentrations of particulate matter in urban atmospheric environment with floors of different heights could not reflect [19]. It also could not fully reflect the close relationship between air pollution and people's living environment [14]. The main reason was that the research on air pollution was restricted by many conditions. At present, there were relatively few professional meteorological monitoring towers in China. The current research was still mainly carried out on the ground. In addition, sampling analysis was disturbed by many factors, such as weather factors, pollution source distribution, and human factors. As a result, there were relatively few studies of the vertical distribution of air pollutants in the atmosphere. People would take the relevant causes first such as room lighting and ventilation into consideration to select the floors of high-rise buildings. Some relevant literature gave 9-11 floors of high-rise buildings as layered areas. Most pollutants would collect among that. There were few studies on this [20]. As a result, it would make people confused when choosing a floor to buy a house. There was also a lack of a certain understanding of the air pollution conditions of high-rise buildings at different heights at the same time. It was impossible to control the atmospheric pollution of floors with different height [21]. Therefore, based on the above existing problems, researches of vertical distribution of atmospheric particles at different heights in high-rise buildings were not enough.

Therefore, to solve this problem, concentrations of outdoor atmospheric particulate matters at different heights in a high-rise building in Xi'an were tested and analyzed in this paper. Variation characteristics of the vertical distribution of particulate matter at different heights were discussed at the same time. It would provide reference significance of controlling the atmospheric particulate matters at the different floors of high-rise buildings.

\section{Methods}

A high-rise building in a university in Xi'an was selected for testing. The latitude and longitude of the test site were 108. $966933 \mathrm{~N}, 34.237085 \mathrm{E}$, and the building was $3.3 \mathrm{~m}$ high, with 29 floors in total. Fig. 1. showed the plan position of the test building, which was about $60 \mathrm{~m}$ away from the main road in the city. The school basketball court, volleyball court and a campus road were directly in front of the building. The arrangement of test points was according to the references to the influence of traffic sources [22]. Testing points included six different floors. There were $1^{\text {st }}, 7^{\text {th }}, 11^{\text {th }}, 17^{\text {th }}, 23^{\text {th }}$, and $27^{\text {th }}$ floors at different heights of the high-rise building. The different heights were $1.5 \mathrm{~m}, 23.1 \mathrm{~m}$, $36.3 \mathrm{~m}, 56.1 \mathrm{~m}, 75.9 \mathrm{~m}$ and $89.1 \mathrm{~m}$ from the ground. The test time was 8:00, 12:00, 15:00, 18:00 and 22:00, respectively. Each test point was tested for 10 minutes. Data were averaged over 10 minutes. The test time was July $202019^{\text {th }}$ to $20^{\text {th }}$.

Table 1. Concentration limits of each pollutant.

\begin{tabular}{|c|c|c|c|c|}
\hline \multirow{2}{*}{ Pollutants } & \multirow{2}{*}{ Average time } & \multicolumn{2}{|c|}{ Concentration limits } & \multirow{2}{*}{ Unit } \\
\hline & & First standard & Secondary standard & \\
\hline \multirow{2}{*}{$\mathrm{PM}_{10}$} & Annual average & 40 & 70 & \multirow{4}{*}{$\mu \mathrm{g} / \mathrm{m}^{3}$} \\
\hline & $24 \mathrm{~h}$ average & 50 & 150 & \\
\hline \multirow{2}{*}{$\mathrm{PM}_{2.5}$} & Annual average & 15 & 35 & \\
\hline & $24 \mathrm{~h}$ average & 35 & 75 & \\
\hline
\end{tabular}


GRIMM1.109 portable aerosol particle size spectrometer was used to measure the concentration of particles in the atmosphere. Measuring range was $0.1 \sim 100.000 \mu \mathrm{g} / \mathrm{m}^{3}$. Counting range was $2000000 \mathrm{P} / \mathrm{L}$, and 31 particle size channels were divided between $0.25 \sim 32 \mu \mathrm{m}$. Repeatability was 5\%. TSI7525 indoor air quality meter measuring instrument was used to measure the temperature and humidity. Measuring range was $0 \sim 60^{\circ} \mathrm{C}$. Measurement accuracy was $\pm 0.6^{\circ} \mathrm{C}$, and resolution was $0.1^{\circ} \mathrm{C}$. Relative humidity measuring range was 5 95\% RH. Measurement accuracy was $\pm 3 \% \mathrm{RH}$, and resolution was $0.1 \% \mathrm{RH}$. HD37AB1347 indoor air quality monitor was used to measure the velocity. Measuring range was $0 \sim 50 \mathrm{~m} / \mathrm{s}$. The measuring accuracy range is $\pm 3 \%$. Table 1 gave a comprehensive reference of the concentration limits of each pollutant according to the standard [23].
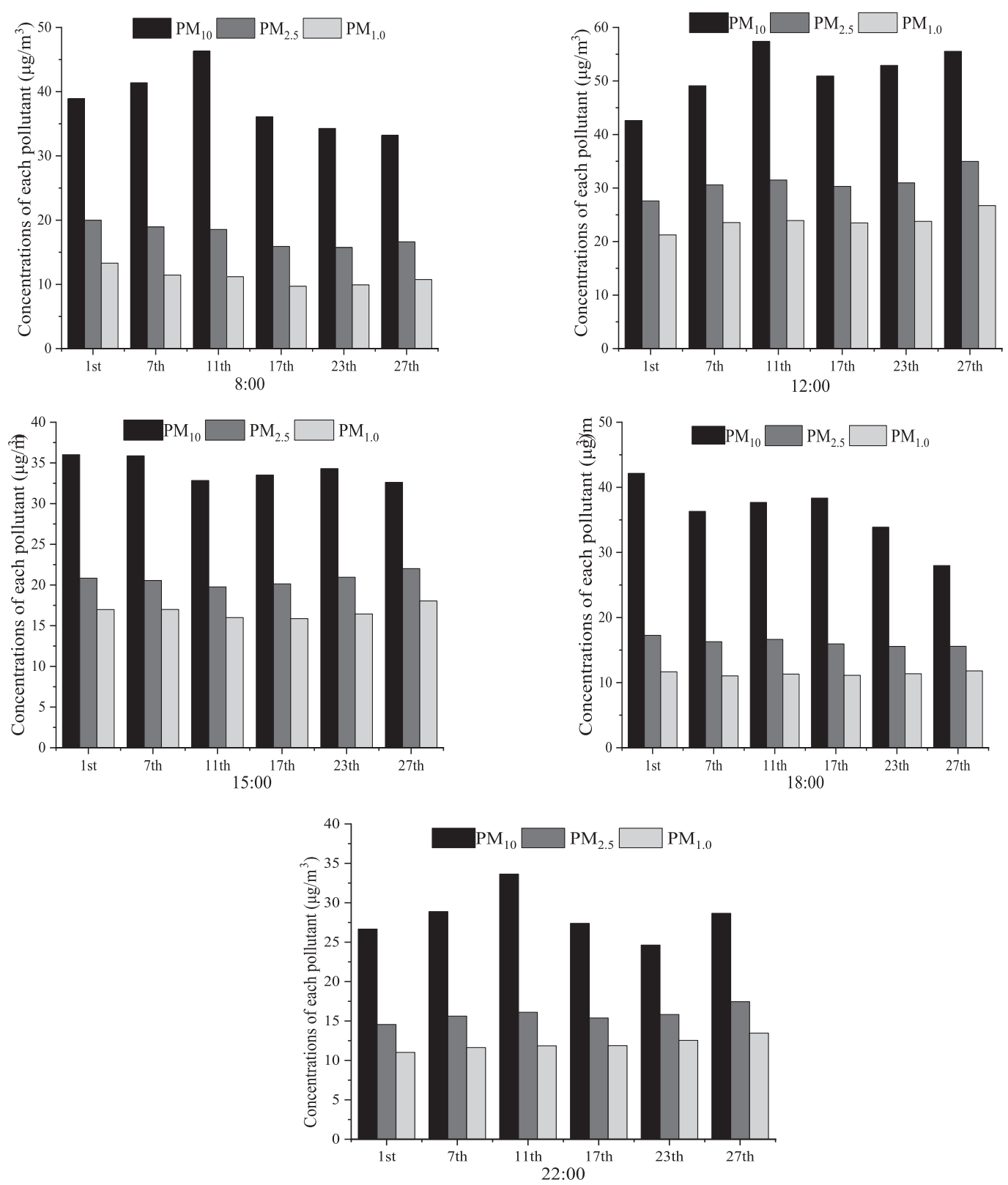

Fig. 2. Variation of particle concentration at different vertical heights.

\section{Results and Discussion}

\section{Variation of the Mass Concentration of Particulate Matter \\ Variation of Particle Concentrations with Different Floors}

When the time was 8:00, with the increase of building height, the mass concentration of $\mathrm{PM}_{10}$ first increased and then decreased. While the mass concentration of $\mathrm{PM}_{2.5}$ and $\mathrm{PM}_{1.0}$ showed a trend of first gradually decreased and then increased. When the time was 12:00, with the increase of building height, the mass concentration of $\mathrm{PM}_{10}, \mathrm{PM}_{2.5}$ and $\mathrm{PM}_{1.0}$ all showed a trend of first increased, and then decreased and next then increased. When the time was 15:00, with 
the increase of building height, the mass concentration of $\mathrm{PM}_{10}$ showed a trend of first decreased, and then increased and next then decreased. While the mass concentration of $\mathrm{PM}_{2.5}$ and $\mathrm{PM}_{10}$ showed a trend of first decreased and then gradually increased. When the time was 18:00, with the increase of building height, the mass concentration of $\mathrm{PM}_{10}$ showed a trend of first decreased, and then increased and next then decreased. While the mass concentration of $\mathrm{PM}_{2.5}$ showed a trend of first gradually decreased, and the mass concentration of $\mathrm{PM}_{1.0}$ was relatively stable and changed not much. When the time was 22:00, with the increase of building height, the mass concentration of $\mathrm{PM}_{10}$ showed a trend of first increased, and then decreased and next then increased. While the mass concentration of $\mathrm{PM}_{25}$ showed a trend of first decreased and then increased, and the mass concentration of $\mathrm{PM}_{1.0}$ was gradually increased. It could be seen that the mass concentrations of each particulate matter at 8:00 and 22:00 were roughly the same changing trend with different height. The main reasons were the temperature was low in the morning and evening, and there was an inversion layer [24]. Particulate matters were not conducive to the diffusion of the atmosphere.

As a result, concentrating particles of the upper air was smaller, while concentrating particles of the ground was more increasing. When the time was 12:00, with the increase of building height, the mass concentration of $\mathrm{PM}_{10}, \mathrm{PM}_{2.5}$ and $\mathrm{PM}_{1.0}$ all showed a trend of first increased, and then decreased and next then increased. The main reasons were that with the increase in solar radiation, the inversion layer near the ground was destroyed, and the influences of human flow increased. As a result, concentrating particles in the upper air increased [25]. The mass concentrations of each particulate matter at 15:00 and 18:00 were roughly the same changing trend with different height. The main reason was that with the solar radiation weakens. The temperature inversion phenomenon gradually decreased, and the concentrations of high-altitude particulate matter would slowly settle down. Therefore, large particles would fluctuate to a certain extent, while small particles were relatively stable. As a result, there was a smaller concentration of particles in the sky and an increase in the concentration of ground particles.

\section{Variation of Average Concentration of Particulates with Different Floors}

With the increase of building height, the mass concentration of $\mathrm{PM}_{10}$ first increased and then decreased. While the mass concentration of $\mathrm{PM}_{2.5}$ and $\mathrm{PM}_{1.0}$ showed a trend of first increased, and then decreased and next then increased. The concentration range of $\mathrm{PM}_{10}$ was 26.3 to $51.8 \mu \mathrm{g} / \mathrm{m}^{3}$, the concentration range of $\mathrm{PM}_{2.5}$ was 14.8 to $26.8 \mu \mathrm{g} / \mathrm{m}^{3}$, and the concentration range of $\mathrm{PM}_{1.0}$ was 9.92 to $21.4 \mu \mathrm{g} / \mathrm{m}^{3}$. The concentration range values showed $\mathrm{PM}_{10}>\mathrm{PM}_{2.5}>\mathrm{PM}_{1.0}$. On the whole, the mass concentrations of particulate matters during the test did not exceed the national secondary standard limit. The mass concentrations of particulate matters in summer were generally low. The data on the $19^{\text {th }}$ were less lower than the value on the $20^{\text {th }}$. The main reason was that it rained in Xi'an the previous day, which showed that rainwater had a good washing effect on particles. The concentration of $\mathrm{PM}_{10}$ in the $27^{\text {th }}$ floor was relatively small, which was $1.67 \mu \mathrm{g} / \mathrm{m}^{3}$ lower than the average mass concentration of $\mathrm{PM}_{10}$ at $1.5 \mathrm{~m}$. The main reason was that large particles were
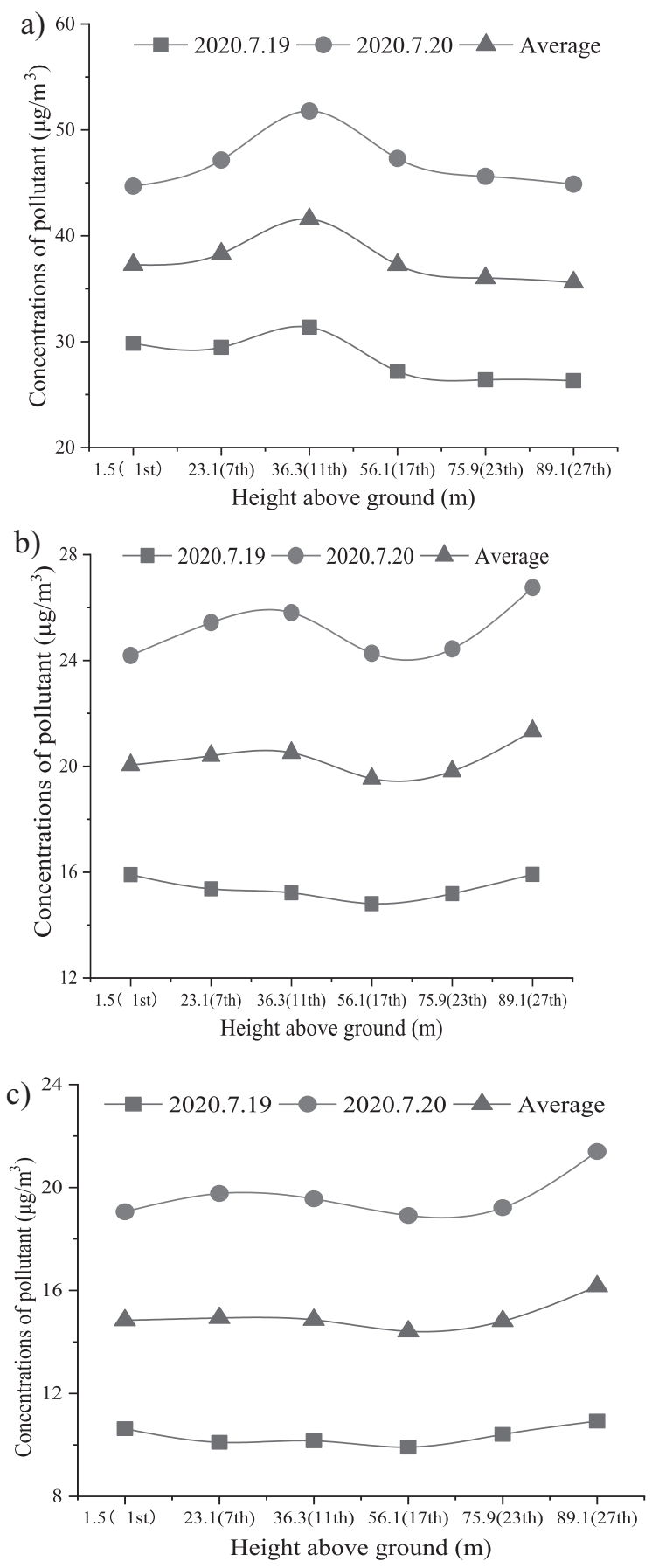

Fig. 3. Variation trend of average particle concentration at different vertical height. a) Variation of $\mathrm{PM}_{10}$ with vertical height b) Variation of $\mathrm{PM}_{2.5}$ with vertical height, c) Variation of $\mathrm{PM}_{1.0}$ with vertical height. 
Table 2. The values of various meteorological factors.

\begin{tabular}{|c|c|c|c|c|c|c|c|c|c|c|}
\hline \multirow{2}{*}{ Date } & \multirow{2}{*}{ Weather } & \multicolumn{3}{|c|}{ Temperature $/\left({ }^{\circ} \mathrm{C}\right)$} & \multicolumn{3}{c|}{ Humidity $/(\%)$} & \multicolumn{3}{c|}{ Wind speed $/(\mathrm{m} / \mathrm{s})$} \\
\cline { 3 - 31 } & & Max & Min & Average & Max & Min & Average & Max & Min & Average \\
\hline $2020-7-19$ & Cloud & 37.8 & 24.7 & 30.1 & 63.7 & 37.3 & 50.6 & 0.71 & 0.09 \\
\hline $2020-7-20$ & Sun & 40.2 & 26.1 & 32.3 & 59.6 & 34.2 & 45.8 & 0.76 & 0.13 \\
\hline
\end{tabular}

Variation of particle concentrations with different time

relatively heavy and they would settle down due to their own gravity. It would cause the concentrations of particulate matters near the ground increased. However, $\mathrm{PM}_{2.5}$ and $\mathrm{PM}_{1.0}$ showed an increased trend on the $27^{\text {th }}$ floor, compared with the average mass concentration of $\mathrm{PM}_{2.5}$ and $\mathrm{PM}_{1.0}$ at $1.5 \mathrm{~m}$, which increased by $1.29 \mu \mathrm{g} / \mathrm{m}^{3}$ and $1.32 \mu \mathrm{g} / \mathrm{m}^{3}$, respectively. This was because the small particles were lighter and they were more easily to diffuse in the air with the flow of air. As a result, concentrations of small particles in the upper air increased.

However, from the figure, the concentrations of different particulate matters changed greatly at the $27^{\text {th }}$ floor, which was $89.1 \mathrm{~m}$ from the ground. It was mainly because the floor of $27^{\text {th }}$ was high from the ground and the surroundings were open. The wind speed was greater than the ground then. The average concentrations of $\mathrm{PM}_{10}, \mathrm{PM}_{2.5}$, and $\mathrm{PM}_{1.0}$ were $35.6 \mu \mathrm{g} / \mathrm{m}^{3}, 21.3 \mu \mathrm{g} / \mathrm{m}^{3}, 16.2 \mu \mathrm{g} / \mathrm{m}^{3}$, respectively. Some related literature showed the concentration distribution of outdoor particulate matters in high-rise buildings had a great relationship with the outdoor wind field $[26,27]$, and there were obvious vortices at different heights. Table 2 showed the relevant values of outdoor meteorological parameters during the test.

With the delay of time, the mass concentration of $\mathrm{PM}_{10}$ first increased, and then decreased, and next then increased and then decreased. While the mass concentration of $\mathrm{PM}_{2.5}$ and $\mathrm{PM}_{1.0}$ showed a trend of first increased, and then gradually decreased. The mass concentration of each particulate matter reached the highest value was at 12:00, which was related to the human activities, living habits, weather and other

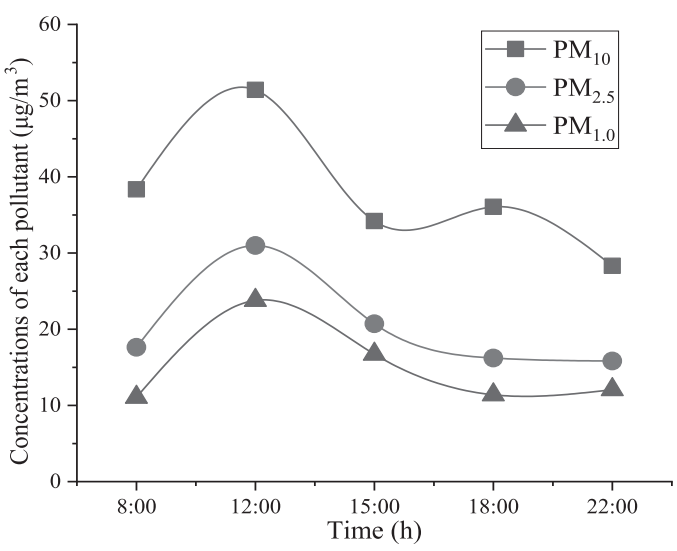

Fig. 4. Variation of particle concentration at different time. conditions of the test location. This was because in the morning under the influence of cold and high pressure, there was often a reverse increase in temperature, and the outdoor temperature was not too high, which was not conducive to the diffusion of fine particles. With the delay of time, there was enough sunshine at 12:00 at noon. With the increase of solar radiation, the ground temperature increased faster, the inversion layer near the ground was destroyed, and atmospheric convection caused the stability of the atmospheric layer to be destroyed [28]. As a result, concentrating of particles in the upper air increased. In addition, the influence of human flow also increased concentrating particles. Because of the increase in the number of students at noon and the increase in cars [29], resuspension of particulate matters intensified. Particulate matters near the ground would gradually diffuse into the upper air with acting wind force [25]. At the time of 15:00, with the temperature inversion phenomenon gradually decreased, and the concentration of particles in the upper air would slowly settle down. When the time was at 18:00, with the peak of off-duty, and the flow of motor vehicles increased sharply. The particulate matters were picked up by the vehicle, and the resuspension effect intensified. Coupled with the effect of catering oil fume, the particulate matter gradually spread into the high air. When the time reached at 22:00 in the night, the ground radiation cool speeded up, and the atmosphere close to the ground quickly cooled down. The greater the influence of the ground, the more the temperature drops, and the inversion gradually formed from the ground. The inversion gradually intensifies, the particles could not gradually diffuse into the upper air. Particles near the ground gradually increased. Some of the large particles in the upper air would gradually settle down by acting gravity. Vertical distribution of particles with different concentrations at different times was mainly affected by the inversion. This conclusion was consistent with the analysis in [30] and it verified the correctness of this article.

\section{Variation of the Counting Concentration of Particulate Matter}

\section{Distribution of Atmospheric Particle Sizes}

Fig. 5. showed distributing among atmospheric particles was given during the test period. With a particle size of 0 to $0.54 \mu \mathrm{m}$ accounted for $98.1 \%$. With 


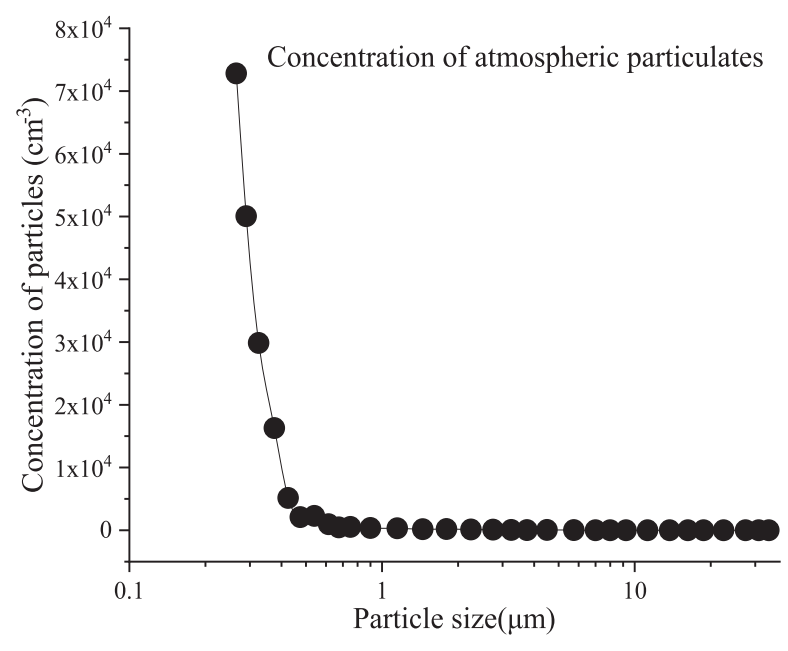

Fig. 5. Distribution of atmospheric particles.

a particle size of 0.54 to $1.0 \mu \mathrm{m}$ accounted for $1.27 \%$. With a particle size of 1.0 to $2.5 \mu \mathrm{m}$ accounted for $0.434 \%$. Particles above $2.5 \mu \mathrm{m}$ accounted for $0.151 \%$. Particle sizes of $0-2.5 \mu \mathrm{m}$ accounted for most of the atmosphere during the testing, accounting for $99.8 \%$. Particle sizes of $0-1.0 \mu \mathrm{m}$ accounted for more than $99.4 \%$. Particles of Xi'an in atmospheric were mainly fine particles. This conclusion was consistent with the literature [31]. Which were easy to enter the human respiratory tract and lungs. They were seriously harmful to human health [32].

\section{Variation of Particle Concentrations with Different Floors}

The percentage of counting concentration of different particle matters to the total counting concentration during the test period was sorted as follows, as shown in Table 3.

With the increase of building height, particles smaller than $1 \mu \mathrm{m}$ showed a trend of first decreased and then gradually increased. While the particles of 1.0-2.5 $\mu \mathrm{m}$ and above $2.5 \mu \mathrm{m}$ all showed a trend of first increased and then gradually decreased. The main reason was that large particles were relatively heavier and they would settle down due to their own gravity,
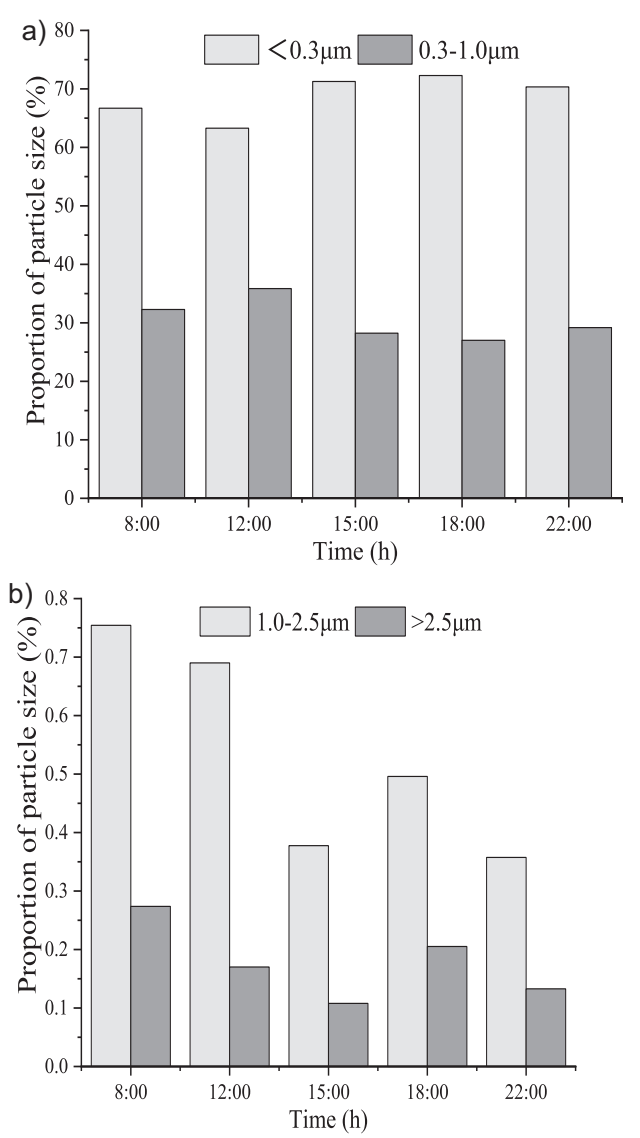

Fig. 6. Variation of particle concentration at different time: a) Particles smaller than $1 \mu \mathrm{m}, \mathrm{b})$ Particles greater than $1 \mu \mathrm{m}$.

while small particles were lighter and they were more susceptible to external influences. Table 4 showed the particles in different particle sizes ranges during the test.

The particles were divided into four particle sizes, which were less than $0.3 \mu \mathrm{m}, 0.3-1.0 \mu \mathrm{m}, 1.0-2.5 \mu \mathrm{m}$, and greater than $2.5 \mu \mathrm{m}$ for statistical analysis. With the delay of time, particles smaller than $0.3 \mu \mathrm{m}$ showed a trend of first decreased, and then increased, and next then decreased. The particles of 0.3-1.0 $\mu \mathrm{m}$ showed a trend of first increased, and then decreased, and next then increased. The particles of 1.0-2.5 $\mu \mathrm{m}$ and larger than $2.5 \mu \mathrm{m}$ all showed a trend of first decreased, and

Table 3. Percentage of each particle sizes concentration.

\begin{tabular}{|c|c|c|c|c|c|c|c|c|}
\hline & \multicolumn{4}{|c|}{$19^{\text {th }}(\%)$} & \multicolumn{4}{c|}{$20^{\text {th }}(\%)$} \\
\hline Floor & $<1.0 \mu \mathrm{m}$ & $1.0-2.5 \mu \mathrm{m}$ & $>2.5 \mu \mathrm{m}$ & $0-2.5 \mu \mathrm{m}$ & $<1.0 \mu \mathrm{m}$ & $1.0-2.5 \mu \mathrm{m}$ & $>2.5 \mu \mathrm{m}$ & $0-2.5 \mu \mathrm{m}$ \\
\hline $1^{\text {st }}$ & 99.14 & 0.660 & 0.202 & 99.80 & 99.58 & 0.303 & 0.120 & 99.88 \\
\hline $7^{\text {th }}$ & 99.06 & 0.728 & 0.217 & 99.78 & 99.56 & 0.314 & 0.122 & 99.88 \\
\hline $11^{\text {th }}$ & 99.09 & 0.699 & 0.214 & 99.79 & 99.52 & 0.337 & 0.144 & 99.86 \\
\hline $17^{\text {th }}$ & 99.11 & 0.696 & 0.194 & 99.81 & 99.56 & 0.313 & 0.129 & 99.87 \\
\hline $23^{\text {th }}$ & 99.17 & 0.656 & 0.176 & 99.82 & 99.57 & 0.305 & 0.121 & 99.88 \\
\hline $2^{\text {th }}$ & 99.23 & 0.615 & 0.157 & 99.84 & 99.62 & 0.283 & 0.100 & 99.90 \\
\hline
\end{tabular}


Table 4. Particle numbers concentration in different size.

\begin{tabular}{|c|c|c|c|c|c|}
\hline Date & Particle sizes $(\mu \mathrm{m})$ & $\operatorname{Max}\left(\mathrm{cm}^{-3}\right)$ & $\operatorname{Min}\left(\mathrm{cm}^{-3}\right)$ & Average $\left(\mathrm{cm}^{-3}\right)$ & Percentage of total (\%) \\
\hline \multirow{6}{*}{$2020-7-19$} & $<0.3$ & 81803 & 17240 & 41625 & 69.4 \\
\hline & $0.3-1.0$ & 28681 & 259 & 3970 & 29.8 \\
\hline & $1.0-2.5$ & 431 & 66 & 202 & 0.674 \\
\hline & $2.5-3.3$ & 138 & 24 & 68 & 0.113 \\
\hline & $3.3-5.0$ & 56 & 16 & 33 & 0.054 \\
\hline & $>5.0$ & 30 & 1 & 3 & 0.025 \\
\hline \multirow{6}{*}{$2020-7-20$} & $<0.3$ & 202328 & 33066 & 84273 & 66.8 \\
\hline & $0.3-1.0$ & 124949 & 163 & 9207 & 32.8 \\
\hline & $1.0-2.5$ & 742 & 70 & 195 & 0.308 \\
\hline & $2.5-3.3$ & 173 & 23 & 79 & 0.063 \\
\hline & $3.3-5.0$ & 100 & 15 & 50 & 0.039 \\
\hline & $>5.0$ & 48 & 1 & 5 & 0.020 \\
\hline
\end{tabular}

Variation of particle concentrations with different time
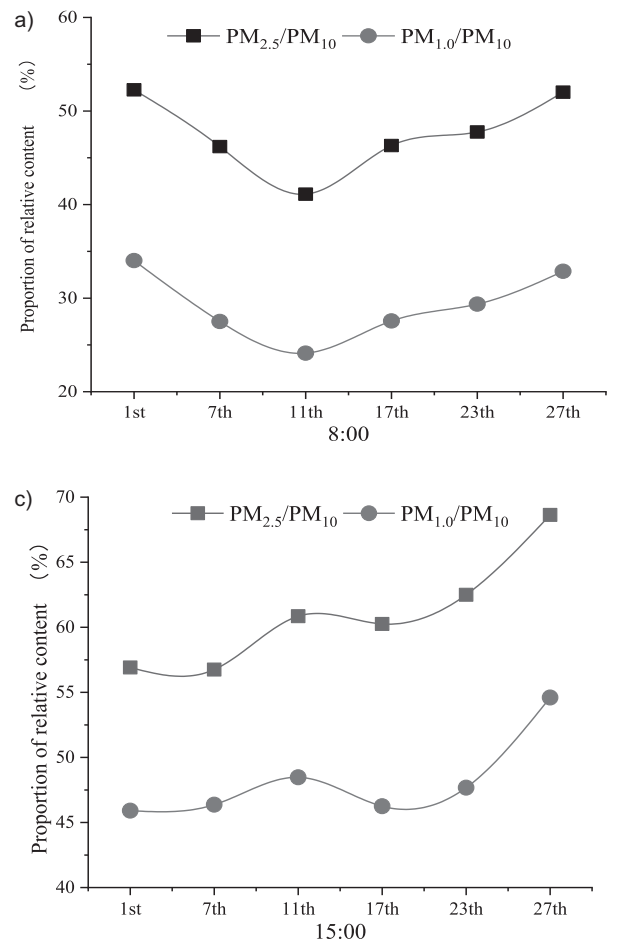
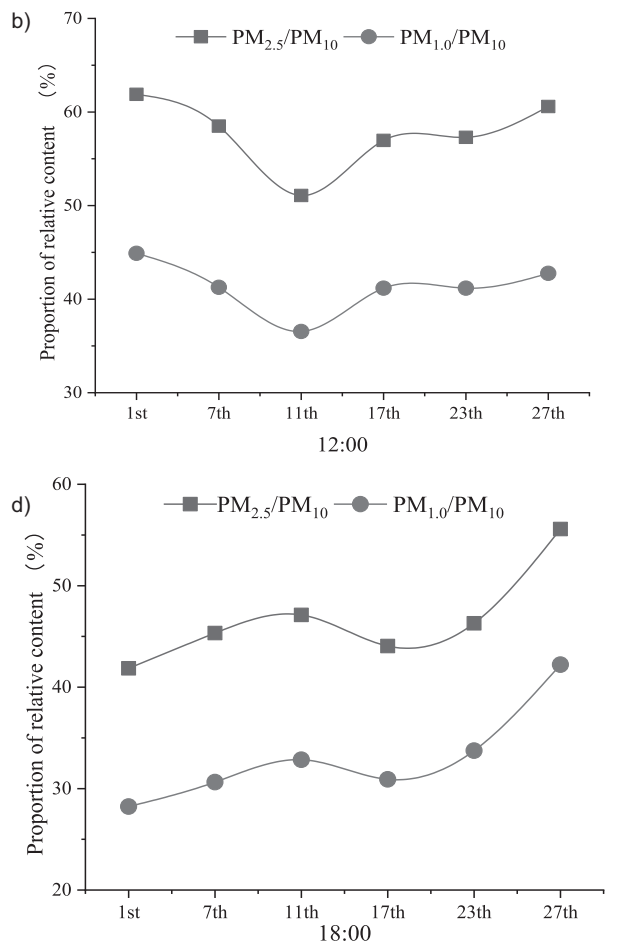

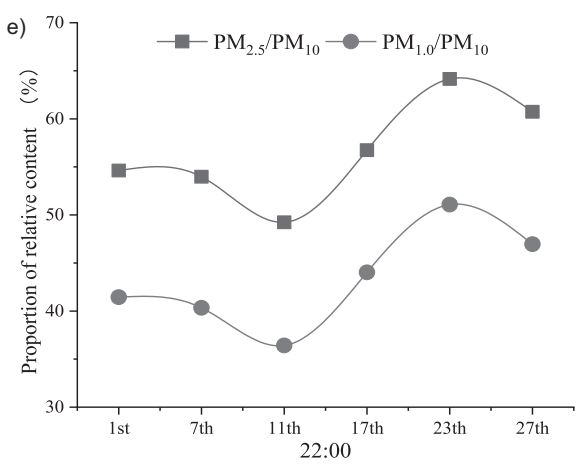

Fig. 7. Variation of $\mathrm{PM}_{2.5} / \mathrm{PM}_{10}, \mathrm{PM}_{1.0} / \mathrm{PM}_{10}$ at different vertical height. 
then increased, and next then decreased. The main reason was that they were affected by temperature, and the counting concentration of particles smaller than $1 \mu \mathrm{m}$ was higher, it was mainly small particles in the atmospheric.

\section{Variation of the Relative Concentration of Particulate Matter}

\section{Variation of Particle Concentrations with Different Floors}

When the time was 8:00 and 12:00, with the increase of building height, both $\mathrm{PM}_{2.5} / \mathrm{PM}_{10}$ and $\mathrm{PM}_{10} / \mathrm{PM}_{10}$ all showed a trend of first decreased and then increased. When the time was 15:00 and 18:00, with the increase of building height, both $\mathrm{PM}_{2.5} / \mathrm{PM}_{10}$ and $\mathrm{PM}_{1.0} / \mathrm{PM}_{10}$ all showed a trend of first increased, and then decreased and next then increased. When the time was 22:00, with the increase of building height, both $\mathrm{PM}_{2.5} / \mathrm{PM}_{10}$ and $\mathrm{PM}_{1.0} / \mathrm{PM}_{10}$ all showed a trend of first decreased, and then increased and next then decreased. The ratio of $\mathrm{PM}_{2.5} / \mathrm{PM}_{10}$ and $\mathrm{PM}_{1.0} / \mathrm{PM}_{10}$ was the highest at 15:00. The main reason was that there was sufficient sunshine at this time. With the increase of solar radiation, the ground temperature increased faster, the inversion layer near the ground was destroyed, and atmospheric convection caused the stability of the atmospheric layer to be destroyed [28]. As a result, the concentration of particles in the upper air increased.

\section{Variation of Average Relative Concentration of Particulates with Different Floors}

With the increase of building height, both $\mathrm{PM}_{2.5} / \mathrm{PM}_{10}$ and $\mathrm{PM}_{1.0} / \mathrm{PM}_{10}$ all showed a trend of first decreased and then increased. The variation range of $\mathrm{PM}_{2.5} / \mathrm{PM}_{10}$ at different height floors was $49.6 \% \sim 61.1 \%$. The variation range of $\mathrm{PM}_{1.0} / \mathrm{PM}_{10}$ at different height floors was $34.1 \% \sim 46.0 \%$. The variation range values showed $\mathrm{PM}_{25} / \mathrm{PM}_{10}>\mathrm{PM}_{10} / \mathrm{PM}_{10}$. It could be seen that the height of the $11^{\text {th }}$ floor was the dividing point, and the ratio of $\mathrm{PM}_{2.5} / \mathrm{PM}_{10}$ and $\mathrm{PM}_{1.0} / \mathrm{PM}_{10}$ was the lowest at this time, while the average ratio of $\mathrm{PM}_{2.5} / \mathrm{PM}_{10}$ and $\mathrm{PM}_{1.0} / \mathrm{PM}_{10}$ was $49.9 \%$ and $35.7 \%$, respectively. The $27^{\text {th }}$ floor had the largest proportion at this time, and the average ratio of $\mathrm{PM}_{2.5} / \mathrm{PM}_{10}$ and $\mathrm{PM}_{1.0} / \mathrm{PM}_{10}$ was $59.5 \%$ and $43.9 \%$, respectively. The highest point was $9.63 \%$ and $8.2 \%$ higher than the lowest point. This was because the small particles were lighter and they were more easily to diffuse in the air with the flow of air. Small particles on the ground would also diffuse into the air because of the influence of human causes. Concentrations of small particles in the upper air increased. While larger particles were heavy, they would settle down because of their own gravity. It would cause the concentrations of particulate matters near the ground increased. However, influences of airflow were different at different vertical height. Some
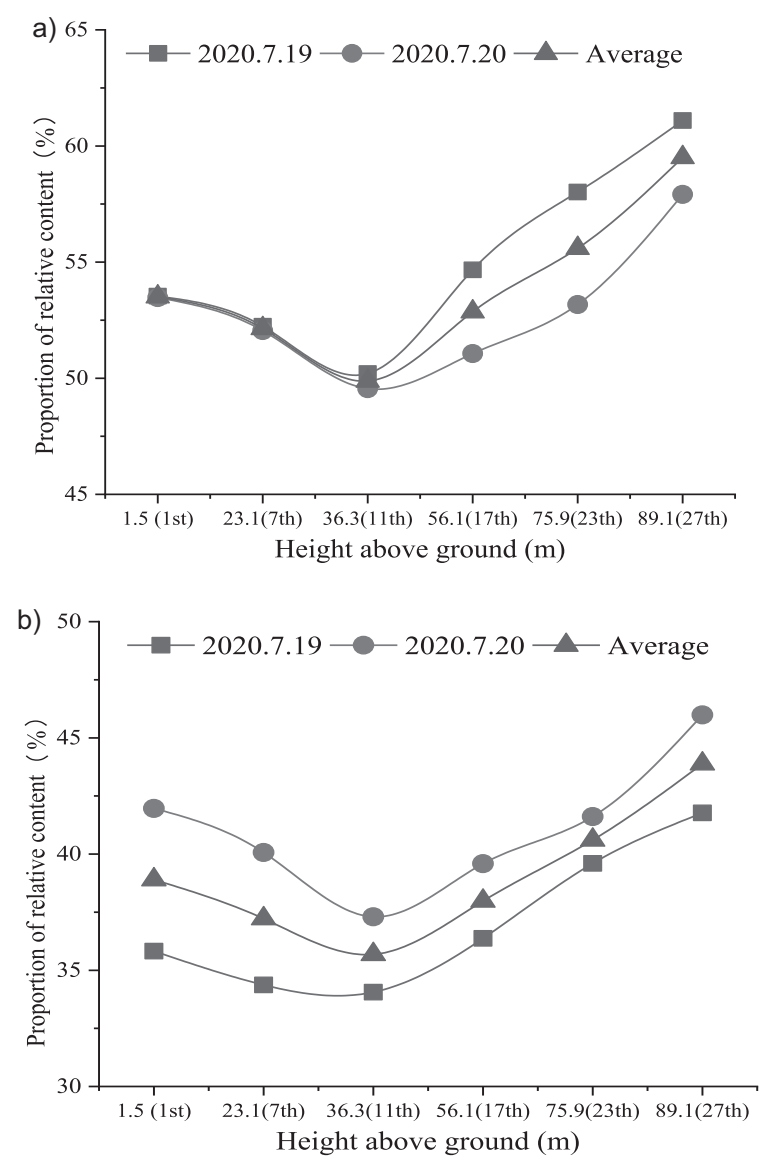

Fig. 8. Variation trend of average relative concentration at different vertical height: a)Variation of $\mathrm{PM}_{2.5} / \mathrm{PM}_{10}$, b) Variation of $\mathrm{PM}_{1.0} / \mathrm{PM}_{10}$.

of these particulate matters would resuspend then. Relative concentration of small particles $\left(\mathrm{PM}_{10} / \mathrm{PM}_{10}\right)$ would increase with vertical height. That was why the relative concentration of $\mathrm{PM}_{10} / \mathrm{PM}_{10}$ in the $27^{\text {th }}$ floor would be higher. There were mainly small particulate matters in atmospheric. This conclusion was consistent with the results of literature $[33,34]$ and it verified the correctness of this article.

\section{Variation of Relative Concentrations with Different Time}

Fig. 9. showed that the relative content of different particulate matters had a fluctuating at different time, and the fluctuation of $\mathrm{PM}_{10} / \mathrm{PM}_{10}$ in different time periods was relatively obvious. Because the number of small particles was large, and the mass was small, which were easy to diffuse in the upper air. The temperature would affect the strength of the diffusion by extension of time. The different temperature would affect the strength of diffusion. The temperature inversion phenomenon in morning and everning would increase the concentration of small particles in the atmosphere, so the concentration of small particles changed greatly. The ratio was highest at the time of 15:00, this was because the time period was for students to go to school 


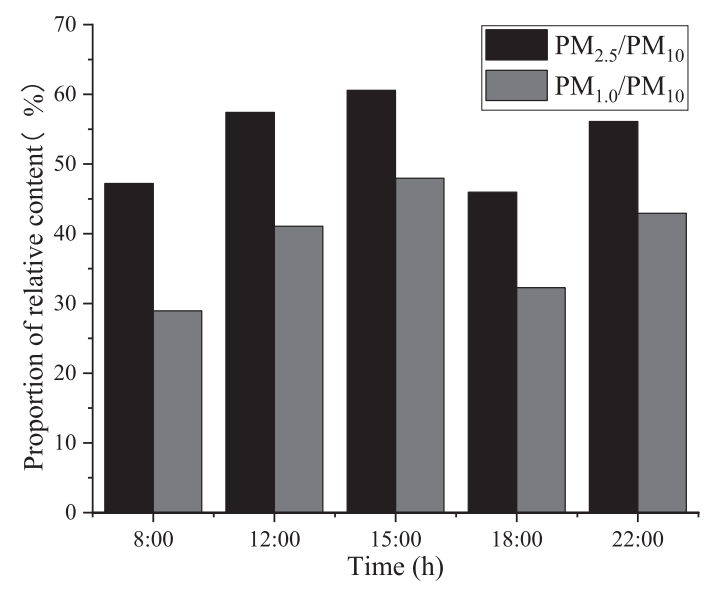

Fig. 9. Variation of $\mathrm{PM}_{2.5} / \mathrm{PM}_{10}, \mathrm{PM}_{1.0} / \mathrm{PM}_{10}$ at different time.

and commute to and from work [29]. The concentration of particulate matters would increase at that time, which lead to the relative content with a relatively large range of variation [19]. The average ratio of $\mathrm{PM}_{2.5} / \mathrm{PM}_{10}$ and $\mathrm{PM}_{1.0} / \mathrm{PM}_{10}$ was $60.6 \%$ and $48.0 \%$, respectively. Relative changes of small particulate matters were larger.

\section{Conclusion}

Vertical distribution characteristics of outdoor particulate matters concentrations of a high-rise building at different heights in a university in Xi'an was tested and analyzed in this paper. Some conclusions were obtained as followed:

1. The concentration of each particulate matter changed the same trend roughly with the increase of vertical height at 8:00 and 22:00, as well as at 15:00 and 18:00. There were differences in $\mathrm{PM}_{10}, \mathrm{PM}_{2.5}$ and $\mathrm{PM}_{1.0}$. While the mass concentration of each particle showed a trend of first increased, then decreased and next then increased with the height increased when the time was 12:00. It caused by the inverse temperature.

2. Particle sizes of $0-2.5 \mu \mathrm{m}$ accounted for most of the atmosphere during the testing, accounting for 99.8\%. Particle sizes of $0-1.0 \mu \mathrm{m}$ accounted for more than $99.4 \%$. Particles of Xi'an in atmosphere were mainly fine particles.

3. With the increase of building height, both $\mathrm{PM}_{2.5} / \mathrm{PM}_{10}$ and $\mathrm{PM}_{1.0} / \mathrm{PM}_{10}$ all showed a trend of first decreased and then increased. The highest point was $9.63 \%$ and $8.2 \%$ higher than the lowest point. The ratio was the highest at the time of 15:00, and the average ratio of $\mathrm{PM}_{2.5} / \mathrm{PM}_{10}$ and $\mathrm{PM}_{1.0} / \mathrm{PM}_{10}$ was $60.6 \%$ and $48.0 \%$, respectively. Relative changes of small particulate matters were larger.

4. Outdoor meteorological conditions would also have a greater impact on the concentration distribution of particulate matters. This paper would provide reference significance of developing high-rise buildings and effectively control of concentrating particulate matters in high-rise buildings.

\section{Acknowledgements}

The work was supported by the National Key R\&D Program of China (NO. 2016YFC0700503) and the Special Research Project of Educational Commission of Shaanxi Province of China (No. 17JK0467).

\section{Conflict of Interest}

The authors declare no conflict of interest.

\section{References}

1. GUAN X.L., WEI H.K., LU S.S., DAI Q., SU H.J. Assessment on the urbanization strategy in China: Achievements, challenges and reflections. Habitat International. 98, 71, 2018.

2. ZENG C., DENG X.Z., DONG J.N., HU P.Y. Urbanization and Sustainability: Comparison of the Processes in "BIC" Countries. Sustainability. 400, 8, 2014.

3. LI L.Y., REN A.L., LIANG Y.Y. The Variation Distribution of the Quality Density and particle size Distribution of Particles in Shijiazhuang. Environmental Science and Management. 61, 32, 2007.

4. CTBUH. CTBUH Height Criteria for Measuring \& Defining Tall Buildings. Council on Tall Buildings and Urban Habitat (CTBUH), n.d.

5. ALGHAMDI M.A. Characteristics and Risk Assessment of Heavy Metals in Airborne PM $_{10}$ from a Residential Area of Northern Jeddah City, Saudi Arabia. Polish Journal of Environmental Studies. 25 (3), 939, 2016.

6. POZZER A., BACER S., DE ZOLT SAPPADINA S., PREDICATORI F., CALEFFI A. Long-term concentrations of fine particulate matter and impact on human health in Verona, Italy. Atmospheric Pollution Research. 5, 737, 2019.

7. ARAVIISKAIA E., BERARDESCA E., BIEBER T., GONTIJO G., VIERA M.S., MARROT L., CHUBERRE B., DRENO B. The impact of airborne pollution on skin. Journal of the European Academy of Dermatology and Venereology. 1501, 33, 2019.

8. FAN X.Y., GAO J.F., PAN K.L., LI D.C., DAI H.H., LI $\mathrm{X}$. More obvious air pollution impacts on variations in bacteria than fungi and their co-occurrences with ammonia-oxidizing microorganisms in $\mathrm{PM}_{2.5}$. Environmental Pollution. 672, 251, 2019.

9. CHEN Q., LUO X.S., CHEN Y., ZHAO Z., HONG Y.W., PANG Y.T., HUANG W.J., WANG Y., JIN L. Seasonally varied cytotoxicity of organic components in $\mathrm{PM}_{2.5}$ from urban and industrial areas of a Chinese megacity. Chemosphere. 428, 230, 2019.

10. SULTAN A.A.A., JUMAAH G.F., ANI F.H.A. Evaluation of the Dispersion of Nitrogen Dioxide and Carbon Monoxide in the Indoor Café-Case Study. Journal of Ecological Engineering. 258, 20, 2019.

11. KINNEY P.L., GICHURU M.G., CLOSE N.V., NGO N., NDIBA P.K., LAW A., GACHANJA A., GAITA S.M., CHILLRUD S.N., SCLAR E. Traffic impacts on PM2.5 air quality in Nairobi, Kenya. Environmental Science and Policy. 373, 14, 2011.

12. PANCZAK R., GALOBARDES B., SPOERRI A., ZWAHLEN M., EGGER M. High life in the sky? 
Mortality by floor of residence in Switzerland. European Journal of Epidemiology. 458, 28, 2013.

13. DAI C., HUANG S.J., PENG H., YI K.X., ZHOU Y.Y., QIN P.F. Particulate pollution status and its characteristics during 2015-2016 in Hunan, China. Atmospheric Pollution Research. 745, 10, 2019.

14. XU Y., YING Q., HU J.L., GAO Y., YANG Y., WANG D.X., ZHANG H.L. Spatial and temporal variations in criteria air pollutants in three typical terrain regions in Shaanxi, China, during 2015. Air Quality Atmosphere and Health. 105, 11, 2018.

15. ZHOU Q.L., WANG C.X., FANG S.J. Application of geographically weighted regression (GWR) in the analysis of the cause of haze pollution in China. Atmospheric Pollution Research. 940, 10, 2019.

16. WANG M.S., CAO J.L., GUI C.L., XU Z.F., SONG D.Y. The Characteristics of Spatiotemporal Distribution of PM2.5 in Henan Province, China. Polish journal of environmental studies. 26 (6), 2789, 2017.

17. ZHU C.L and MA L. Contamination status and correlation analysis of particulate matter and gaseous pollutants in the early heating period in Xi'an. Environmental Engineering. 84, 35, 2017.

18. SUN R., XIAO Z.M., HAN S.Q., CHEN K., DING J., WU J.H., ZHANG Y.F., FENG Y.C.Vertical distribution characteristics of particulate matter at surface layer in winter of Tianjin. Acta Scientiae Circumstantiae. 37, 2252, 2017.

19. GUO B., REN A.L., LI L.Y., ZHAO W.X. The vertical distribution characteristics of respirable particles in autumn of Shijiazhuang. Journal of the Graduate School of the Chinese Academy of Sciences. 714, 24, 2007.

20. WU C.D., NAUGHTON P.M., MELLY S., LANE K., ADAMKIEWICZ G., DURANT J.L., BRUGGE D., SPENGLER J.D. Mapping the vertical distribution of population and particulate air pollution in a nearhighway urban neighborhood: Implications for exposure assessment. Journal of Exposure Science and Environmental Epidemiology. 299, 24, 2014.

21. GUPTA S., KHARE M., GOYAL R. Sick building syndrome - A case study in a multistory centrally airconditioned building in the Delhi City. Building and Environment. 2805, 42, 2007.

22. GB/T18883-2002. Indoor air quality standard. China Environmental Science Press. 2002.
23. GB3095-2012. Ambient air quality standards. China Environmental Science Press. 2012.

24. DENG P.Y. Study on multilayer temperature inversion and its environmental effects in Chengdu area. Chengdu: Chengdu University of Information Technology, 2019.

25. ZHANG J.H., XU S.R., ZHAO S.M. Analysis of Effect of Temperature Inversion to Atmosphere Pollution. Heilongjiang Environmental Journal. 25, 33, 2008.

26. AZIMI P., ZHAO H.R., FAZLI T., ZHAO D., FARAMARZI A., LEUNG L., STEPHENS B. Pilot study of the vertical variations in outdoor pollutant concentrations and environmental conditions along the height of a tall building. Building and Environment. 132, 138, 2018.

27. ZHAO X.W., FAN Y.S., SI P.F., ZHAO S.W., GOUZ.Z. Pollution Characteristics of Indoor and Outdoor Particulate of Buildings. Journal of Environmental Engineering Technology. 6, 226, 2016.

28. TIAN X., ZHAO W.J., CUI M.Y., JIN W.X., WU Y.H. Vertical Distribution of $\mathrm{PM}_{25}$ in Near Surface - a Case Study of an University in Beijing. Journal of Capital Normal University (Natural Science Edition). 93, 39, 2018.

29. PENG Z.M., WU Q.Q., WANG D.F., LI M. TemporalSpatial Pattern and Influencing Factors of China's Province-Level Transport Sector Carbon Emissions Efficiency. Polish Journal of Environmental Studies. 29 (1), 234, 2020.

30. SUN M.L., MU H.B., WU D.Z., YAO Q., LIU D.Y. Vertical Distribution Characteristics of PM2.5 Mass Concentration in the Atmosphere over Tianjin. Meteorological Monthly. 63, 34, 2008

31. ZHANG H. 1. Experimental Study of Filters of Different Grades on Outdoor Airborne Particulate Matter. Xi'an: Xi'an University of Architecture and Technology, 2018.

32. BABAYEMI J.O., OGUNDIRAN M.B., OSIBANJO O. Overview of environmental hazards and health effects of pollution in developing countries: a case study of Nigeria. Environment Quality Management. 26, 64, 2016.

33. ZHANG L. The Meteorological Characteristics Effecting Concentration of $\mathrm{PM}_{10}$ and $\mathrm{PM}_{2.5}$ in Yanta District of Xi'an. Xi'an: Xi'an University of Architecture and Technology, 2015.

34. ZHANG H.L. Experimental Study of Filters of Different Grades on Outdoor Airborne Particulate Matter. Xi'an: Xi'an University of Architecture and Technology, 2018. 